\title{
Effects of Breeder Age on Genetic Parameter Estimates of Slaughter and Carcass Traits in Japanese Quail
}

\author{
Eser Kemal Gurcan ${ }^{1 a}$, Dogan Narinc ${ }^{2}$, Selcuk Kaplan ${ }^{2}$
}

${ }^{1}$ Department of Animal Science, Faculty of Agriculture, Namık Kemal University, 59030, Tekirdağ, Turkey

${ }^{2}$ Department of Genetics, Faculty of Veterinary Medicine, Namık Kemal University, 59030, Tekirdağ, Turkey

\begin{abstract}
This study aimed to determine the phenotypic values of the slaughter and carcass traits in the flocks of quails obtained when a flock of parent quails were at 12,16, and 20 weeks of age and to estimate the heritabilities and the genetic correlations for these traits. For this purpose, a total of 1,346 Japanese quails were slaughtered at 8 weeks of age, and their slaughter weights as well as carcass, breast, leg, and abdominal fat weights and ratios were determined. Differences in all traits were detected between female and male quails $(\mathrm{P}<0.05)$. The averages of many important traits, primarily slaughter weight, carcass weight, and breast weight, increased with the increase in the breeder age. On the contrary, the carcass yield decreased $(\mathrm{P}<0.05)$. There were no significant variations in the phenotypic and genetic variances for the slaughter and carcass traits in the flocks obtained when the breeder flock was at different ages. The heritabilities for slaughter weight, carcass weight, and abdominal fat weight were estimated to be moderate, and the genetic correlations among them were estimated to be positive and high. In conclusion, it is possible to state that positive results might be obtained by using the carcass ratio as the criterion for selection in quails. Besides, the breeder age was discovered to have had no significant effect on the genetic parameter estimations.
\end{abstract}

Keywords: Abdominal fat, Carcass yield, Genetic correlation, Heritability, Maternal age

\section{Introduction}

Although it is known that the breeder age directly affects many economically important traits in poultry, there are some contradictions about the nature of the effect concerned. The weights of eggs and, accordingly, the weights of the chicks obtained increase with an increase in the breeder age (Şahan et al., 2014; İpek and Sözcü, 2015). Higher mortality (Wyatt et al., 1985) and lower yolk nutrients (Şahan et al., 2014) are observed in the eggs obtained from young breeders, whereas the bone width is higher in the embryos obtained from old hens (Alfonso-Torres et al., 2009). Shanawany (1987) and Peebles et al. (1999a) put forward that the increase in the hatching weights of the chicks depending on the breeder age significantly increased the weights on the following weeks. On the contrary, İpek and Sözcü (2015) reported that the chicks obtained from young breeders reached the weights of the chicks obtained from old breeders even when they were only at one week of age. Ulmer-Franco et al. (2010) and El Sabry et al. (2013) reported that the broilers obtained from old breeders had higher live weights and better feed conversion. Contrary to these views, Hulet et al. (2007) set forth that there was no difference between the live weights of the broilers obtained from the breeders at different ages.

Different views were also available in the few studies on how slaughter and carcass traits changed in the flocks obtained from the breeders at different ages, apart from the traits of embryonic development, posthatch growth, and feed conversion. Some researchers suggested that the slaughter traits were unaffected by the breeder age (Joseph and Moran, 2005; Çabuk et al., 2006; Onbaşılar et al., 2008). The results of some studies demonstrated that the carcass yield improved with an increase in the breeder age (Shanawany, 1987; Triyuwanta et al., 1992; Peebles et al., 1999b; Viera and Moran, 1998). Furthermore, some researchers 
claimed that the breeder age affected slaughter and carcass traits, but this effect was unsystematic (Vali et al., 2005; Akbarnejad et al., 2015).

As seen, one encounters different results with respect to the effect of the breeder age on slaughter \& carcass traits in poultry. In their studies, Lotfi et al. (2011) and Khaldari et al. (2011), who estimated genetic parameters for slaughter and carcass traits in Japanese quails, reported that the breeder age (or hatch) affected the model parameters. In a study by Zerehdaran et al. (2004), some 3,278 progenies were obtained from a base flock on 13 different weeks between 1999 and 2000. In the study concerned, where genetic parameters for carcass-related traits were estimated, it was reported that the breeder age was effective on slaughter weight, carcass weight, and yield, breast weight and yield, and abdominal fat weight and yield. Nevertheless, no findings on how the breeder age affected phenotypic or genetic parameters were presented in these studies. This study aimed to determine the phenotypic values for slaughter and carcass traits in the flocks of quails obtained when a flock of parent quails were at 12, 16, and 20 weeks of age and to estimate the multi-trait heritabilites and genetic correlations for the traits.

\section{Material and Methods}

The research was carried out at Namık Kemal University, and the Japanese quail (Coturnix coturnix Japonica) was used as the animal material. The document by the ethics committee for the study was obtained from the Local Ethics Committee for Animal Experiments at Namık Kemal University and its number is 2015/09-3. A flock of parents was generated from unselected and randomly mating quails (40 males and 120 females) in the study. The breeder quails were placed into individual egg cages (210 $\mathrm{cm}^{2}$ /quail) to have each female at one division, and the family structures were created by allocating one male individual for every three females (the males were mated with one female in their respective families every day). The eggs collected for 7 days when the breeder quails were at 12,16, and 20 weeks of age were placed into an incubator. Wing numbers were attached to the chicks coming out of the incubator, and they were kept in group-type growing cages with a heater for three weeks $\left(82.56 \mathrm{~cm}^{2} /\right.$ quail $)$. The quails were later taken into fattening cages $\left(150 \mathrm{~cm}^{2} /\right.$ quail), and their slaughter and carcass traits at 8 weeks of age were measured. The breeder quails were fed a feed containing $24 \% \mathrm{CP}$ and 2,900 kcal/kg of ME for the first three weeks and a feed containing $20 \% \mathrm{CP}, 2,800 \mathrm{kcal} / \mathrm{kg}$ of ME, and $2.5 \% \mathrm{Ca}$ after the three weeks. The juvenile flocks were fed a feed containing $24 \% \mathrm{CP}$ and 2,900 kcal/kg of ME from hatching to 8 weeks of slaughter age. The quails were treated with lighting for 23 hours per day, and feed and water were provided ad libitum. A total of 1,516 quails in each of the three slaughter flocks obtained when the breeders were at 12 , 16 , and 20 weeks of age, the 1,346 that remained after the $11.21 \%$ mortality rate occurring in the rearing period were referred to slaughtering at 56 days of age. Feed had been removed for 4 hours before slaughtering, and the slaughter weights of the quails (BW) were determined. During the slaughter, all weights were measured with a digital scale with $0.01 \mathrm{~g}$ sensitivity. Following wet plucking and dissection during the slaughter, their hot carcass and abdominal fat (AFW) weights were determined to include the neck and abdominal fat but to exclude the edible internal organs (Yalçın et al., 1995). After leaving the carcasses at $+4^{\circ} \mathrm{C}$ for a day, the cold carcass weight $(\mathrm{CW})$ was measured; the carcasses were fragmented; and the breasts (BRW) and the legs (LW) were measured. By calculating the ratios of cold carcass, abdominal fat, breast weight and leg weight to the slaughter weight, phenotypic values were obtained for cold carcass ratio (CY), abdominal fat ratio (AFY), breast ratio (BRY), and leg ratio (LY), respectively.

The following mixed linear model was used for the statistical analysis of the data for the traits of BW, CW, BRW, LW, AFW, CY, BRY, LY, and AFY in the slaughter flocks:

$\mathbf{y}=\mathbf{X} \boldsymbol{\beta}+\mathbf{Z u}+\mathbf{e}$

The $\mathbf{y}$ in the model is the vector which encompasses the observation values for each trait and it is in the form of $\mathbf{y} \mathbf{N}(\boldsymbol{\mu}, \mathbf{V})$, where it displays a multivariate normal distribution whose vector of means is $\boldsymbol{\mu}$ and variance-covariance matrix is $\mathbf{V} . \mathbf{X}$ is the pattern matrix for the fixed effects, while $\boldsymbol{\beta}$ is the vector of fixed effects. Sex was used as the fixed effect in the analyses made individually for each breeder age. $\mathbf{Z}$ is the pattern matrix for the random effects, whereas $\mathbf{u}$ is the vector of additive genetic effects. The model includes such definitions as $\mathbf{E}(\mathbf{y})=\mathbf{X} \boldsymbol{\beta}, \operatorname{var}(\mathbf{u})=\mathbf{G}, \operatorname{var}(\mathbf{e})=\mathbf{R}$, and $\operatorname{var}(\mathbf{y})=\mathbf{Z G Z}+\mathbf{R}$ (Mrode, 2005), where the $\mathbf{G}$ matrices are the variance-covariance matrices which represent the additive genetic effects in the slaughter flocks, while the $\mathbf{R}$ matrices are the variance-covariance matrices which represent the error. In the study, the PROC MIXED procedure of the SAS program was employed to estimate the additive genetic (G) and error (R) variance-covariance components with the REML method (SAS Institute, 2011). In the analyses whereby 
the three slaughter flocks would be evaluated collectively, the $\mathbf{X}$ pattern matrix for the fixed effects above and the $\boldsymbol{\beta}$ vector of fixed effects were designed to have 3 levels (the effect of breeder age). The heritabilities $\left(h^{2}\right)$ for the traits, the genetic correlations among the traits $\left(r_{G}\right)$ and the standard error values were estimated by using the IML (interactive matrix language) procedure of the SAS program (SAS Institute, 2011).

\section{Results and Discussion}

The descriptive statistics of the BW, CW, CY, BRW, BRY, LW, LY, AFW, and AFY belonging to a total of 1,346 quails included in the study are presented in Table 1. Moreover, Table 1 also contains the results of the test for analysis of variance and the multiple comparison tests in which the averages of the quails for the traits are compared in terms of breeder ages and sexes. As also seen from the table, the breeder age was effective on all traits other than BRY, LW, and AFW ( $\mathrm{P}<0.05)$. Data about a total of 642 female and 704 male quails were evaluated in the study, and it was discovered that there were differences in the averages of all traits other than AFY between the sexes $(\mathrm{P}<0.05)$. It was established that the females had

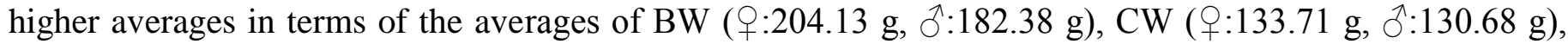
BRW (

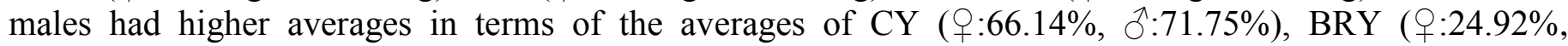

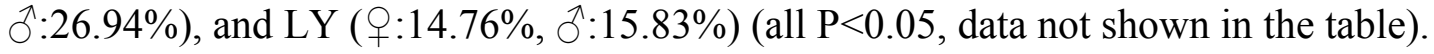

Table 1: The descriptive statistics and effects of breeder age and sex on slaughter and carcass traits in Japanese quail

\begin{tabular}{|c|c|c|c|c|c|c|c|c|}
\hline Trait & $\begin{array}{l}\text { Breder } \\
\text { Age }\end{array}$ & Mean & SE & $\mathrm{CV}(\%)$ & Min. & Max. & $\begin{array}{c}\text { P (Breeder } \\
\text { Age) }\end{array}$ & $\mathrm{P}(\mathrm{Sex})$ \\
\hline \multirow[t]{3}{*}{$\mathrm{BW}, \mathrm{g}$} & 12 & $186.69^{c}$ & 1.26 & 12.08 & 140.06 & 248.95 & \multirow[t]{3}{*}{$0.000 *$} & \multirow[t]{3}{*}{$0.000 *$} \\
\hline & 16 & $191.04^{b}$ & 1.18 & 11.32 & 143.27 & 255.00 & & \\
\hline & 20 & $196.43^{\mathrm{a}}$ & 0.98 & 13.07 & 137.82 & 272.00 & & \\
\hline \multirow[t]{3}{*}{$\mathrm{CW}, \mathrm{g}$} & 12 & $128.80^{b}$ & 0.77 & 10.73 & 80.21 & 179.16 & \multirow[t]{3}{*}{$0.000 *$} & \multirow[t]{3}{*}{$0.000 *$} \\
\hline & 16 & $131.94^{\mathrm{a}}$ & 0.69 & 9.59 & 93.52 & 183.5 & & \\
\hline & 20 & $133.77^{\mathrm{a}}$ & 0.57 & 11.11 & 95.24 & 196.55 & & \\
\hline \multirow[t]{3}{*}{$\mathrm{CY}, \%$} & 12 & $69.29^{\mathrm{a}}$ & 0.29 & 7.60 & 53.12 & 79.04 & \multirow[t]{3}{*}{$0.018^{*}$} & \multirow[t]{3}{*}{$0.000 *$} \\
\hline & 16 & $69.49^{\mathrm{a}}$ & 0.30 & 7.91 & 57.46 & 81.10 & & \\
\hline & 20 & $68.77^{\mathrm{b}}$ & 0.19 & 7.42 & 56.38 & 79.64 & & \\
\hline \multirow[t]{3}{*}{ BRW, g } & 12 & $48.49^{b}$ & 0.38 & 14.19 & 23.85 & 69.94 & \multirow[t]{3}{*}{$0.000 *$} & \multirow[t]{3}{*}{$0.000 *$} \\
\hline & 16 & $49.26^{\mathrm{b}}$ & 0.34 & 12.52 & 30.12 & 71.12 & & \\
\hline & 20 & $50.78^{\mathrm{a}}$ & 0.25 & 13.02 & 35.48 & 75.59 & & \\
\hline \multirow[t]{3}{*}{ BRY, \% } & 12 & 26.05 & 0.16 & 11.04 & 15.79 & 34.24 & \multirow[t]{3}{*}{0.711} & \multirow[t]{3}{*}{$0.000 *$} \\
\hline & 16 & 25.88 & 0.15 & 10.50 & 18.79 & 39.45 & & \\
\hline & 20 & 25.99 & 0.10 & 9.76 & 19.73 & 33.23 & & \\
\hline \multirow[t]{3}{*}{ LW, g } & 12 & 29.21 & 0.19 & 11.9 & 18.25 & 39.25 & \multirow[t]{3}{*}{0.397} & \multirow[t]{3}{*}{$0.000 *$} \\
\hline & 16 & 29.11 & 0.18 & 11.18 & 20.82 & 46.25 & & \\
\hline & 20 & 29.4 & 0.13 & 11.44 & 20.64 & 45.32 & & \\
\hline \multirow[t]{3}{*}{$\mathrm{LY}, \%$} & 12 & $15.73^{\mathrm{a}}$ & 0.08 & 9.11 & 11.14 & 20.57 & \multirow[t]{3}{*}{$0.000 *$} & \multirow[t]{3}{*}{$0.000 *$} \\
\hline & 16 & $15.41^{b}$ & 0.08 & 9.85 & 11.41 & 22.91 & & \\
\hline & 20 & $15.08^{\mathrm{c}}$ & 0.05 & 8.45 & 11.11 & 19.07 & & \\
\hline \multirow[t]{3}{*}{ AFW, $\mathrm{g}$} & 12 & 2.22 & 0.07 & 57.22 & 0.12 & 6.63 & \multirow[t]{3}{*}{0.066} & \multirow[t]{3}{*}{$0.003 *$} \\
\hline & 16 & 2.12 & 0.07 & 56.69 & 0.11 & 6.91 & & \\
\hline & 20 & 2.32 & 0.05 & 56.10 & 0.15 & 6.75 & & \\
\hline \multirow[t]{3}{*}{$\mathrm{AFY}, \%$} & 12 & 1.17 & 0.04 & 53.98 & 0.07 & 3.46 & \multirow[t]{3}{*}{0.189} & \multirow[t]{3}{*}{0.813} \\
\hline & 16 & 1.10 & 0.03 & 53.88 & 0.07 & 3.46 & & \\
\hline & 20 & 1.17 & 0.02 & 53.11 & 0.07 & 3.61 & & \\
\hline
\end{tabular}

Notice: body weight (BW), carcass weight (CW), carcass yield (CY), breast weight (BRW), breast yield (BRY), leg weight (LW), leg yield (LY), abdominal fat weight (AFW), abdominal fat yield (AFY)The shares of the phenotypic variances for BW, CW, CY, BRW, BRY, LW, LY, AFW, and AFY according to 
the breeder ages and the general situation in terms of sire, dam, and error components and the estimations of heritabilities are presented in Table 2. In Table 2, it is seen that the total variances for each trait did not vary very much according to the breeder ages. The heritability for BW were close to each other in the flocks obtained at different breeder ages (0.32-0.37), and these estimations were at moderate levels. The heritabilities were found at high levels (0.40-49) for $\mathrm{CW}$ in the flocks obtained at different breeder ages, while the general heritability was found moderate to high $(0.36)$. The moderate heritability estimates $(0.27$ and 0.30, respectively) were likewise determined for BRW and LW. The heritabilities estimated for all other traits were low and low to moderate.

Table 2: Variance component and heritability estimates by breeder age of slaughter and carcass traits in Japanese quail

\begin{tabular}{|c|c|c|c|c|c|c|c|c|c|c|}
\hline & SV & BW & $\mathrm{CW}$ & $\mathrm{CY}$ & BRW & BRY & LW & LY & AFW & AFY \\
\hline \multirow{4}{*}{$\begin{array}{l}\text { Breeder } \\
\text { Age } \\
12\end{array}$} & $\sigma_{\text {Sire }}^{2}$ & 28.10 & 8.94 & 1.11 & 0.64 & 0.33 & 0.75 & 0.19 & 0.07 & 0.02 \\
\hline & $\sigma_{\text {Dam }}^{2}$ & 65.27 & 35.82 & 1.16 & 6.99 & 0.30 & 2.52 & 0.02 & 0.08 & 0.01 \\
\hline & $\sigma_{\text {Error }}^{2}$ & 415.70 & 147.32 & 25.59 & 40.20 & 7.71 & 8.82 & 1.85 & 1.46 & 0.37 \\
\hline & $h^{2}$ & 0.37 & 0.47 & 0.16 & 0.32 & 0.15 & 0.54 & 0.21 & 0.20 & 0.16 \\
\hline \multirow{4}{*}{$\begin{array}{l}\text { Breeder } \\
\text { Age } \\
16\end{array}$} & $\sigma_{\text {Sire }}^{2}$ & 32.25 & 20.86 & 1.36 & 2.47 & 0.28 & 0.91 & 0.04 & 0.04 & 0.00 \\
\hline & $\sigma_{\text {Dam }}^{2}$ & 46.00 & 18.37 & 0.34 & 3.70 & 0.15 & 0.55 & 0.14 & 0.12 & 0.03 \\
\hline & $\sigma_{\text {Error }}^{2}$ & 389.09 & 120.08 & 28.58 & 31.76 & 6.98 & 9.15 & 2.14 & 1.30 & 0.32 \\
\hline & $h^{2}$ & 0.33 & 0.49 & 0.11 & 0.33 & 0.12 & 0.27 & 0.15 & 0.21 & 0.16 \\
\hline \multirow{4}{*}{$\begin{array}{l}\text { Breeder } \\
\text { Age } \\
20\end{array}$} & $\sigma_{\text {Sire }}^{2}$ & 91.58 & 30.79 & 1.63 & 5.36 & 0.29 & 1.14 & 0.03 & 0.12 & 0.03 \\
\hline & $\sigma_{\text {Dam }}^{2}$ & 13.54 & 13.69 & 0.36 & 1.82 & 0.21 & 1.09 & 0.10 & 0.05 & 0.00 \\
\hline & $\sigma_{\text {Error }}^{2}$ & 556.14 & 176.33 & 24.03 & 36.60 & 5.97 & 9.14 & 1.50 & 1.54 & 0.36 \\
\hline & $h^{2}$ & 0.32 & 0.40 & 0.15 & 0.33 & 0.15 & 0.39 & 0.16 & 0.19 & 0.16 \\
\hline \multirow[t]{4}{*}{ General } & $\sigma_{\text {Sire }}^{2}$ & 78.25 & 27.15 & 1.32 & 4.12 & 0.31 & 1.04 & 0.06 & 0.10 & 0.02 \\
\hline & $\sigma_{\text {Dam }}^{2}$ & 17.94 & 9.07 & 0.59 & 1.77 & 0.16 & 0.64 & 0.04 & 0.07 & 0.01 \\
\hline & $\sigma_{\text {Error }}^{2}$ & 502.60 & 165.95 & 25.68 & 38.25 & 6.64 & 9.55 & 1.87 & 1.46 & 0.35 \\
\hline & $h^{2}$ & 0.32 & 0.36 & 0.14 & 0.27 & 0.13 & 0.30 & 0.10 & 0.21 & 0.18 \\
\hline
\end{tabular}

Notice: source of variation (SV), body weight $(\mathrm{BW})$, carcass weight $(\mathrm{CW})$, carcass yield $(\mathrm{CY})$, breast weight (BRW), breast yield (BRY), leg weight (LW), leg yield (LY), abdominal fat weight (AFW), abdominal fat yield (AFY)

The genetic correlations among BW, CW, BRW, LW, AFW, CY, BRY, LY, and AFY are presented in Table 3. The genetic correlations between BW and CW, BRW, and LW were estimated to be positive and high. Besides, the genetic correlations between CY and BRY and LY were also estimated to be positive and high.

Table 3: Genetic correlation estimates and SE (in parentheses) of slaughter and carcass traits in Japanese quail

\begin{tabular}{|l|c|c|c|c|c|c|c|c|c|}
\hline & BW & CW & BRW & LW & AFW & CY & BRY & LY & AFY \\
\hline BW & 0.32 & & & & & & & & \\
& $(0.01)$ & & & & & & & & \\
\hline CW & 0.94 & 0.36 & & & & & & & \\
& $(0.01)$ & $(0.01)$ & & & & & & & \\
\hline BRW & 0.86 & 0.95 & 0.27 & & & & & & \\
& $(0.01)$ & $(0.01)$ & $(0.01)$ & & & & & & \\
\hline LW & 0.95 & 0.98 & 0.89 & 0.30 & & & & & \\
& $(0.01)$ & $(0.00)$ & $(0.01)$ & $(0.01)$ & & & & & \\
\hline AFW & 0.70 & 0.61 & 0.44 & 0.46 & 0.21 & & & & \\
& $(0.01)$ & $(0.02)$ & $(0.02)$ & $(0.02)$ & $(0.02)$ & & & & \\
\hline CY & -0.42 & -0.10 & 0.03 & -0.16 & -0.31 & 0.14 & & & \\
& $(0.02)$ & $(0.07)$ & $(0.08)$ & $(0.06)$ & $(0.03)$ & $(0.02)$ & & & \\
\hline BRY & -0.31 & -0.04 & 0.21 & -0.17 & -0.21 & 0.83 & 0.13 & & \\
& $(0.04)$ & $(0.09)$ & $(0.07)$ & $(0.05)$ & $(0.05)$ & $(0.01)$ & $(0.02)$ & & \\
\hline LY & -0.44 & -0.11 & -0.10 & -0.09 & -0.44 & 0.89 & 0.55 & 0.10 & \\
& $(0.03)$ & $(0.08)$ & $(0.05)$ & $(0.08)$ & $(0.02)$ & $(0.01)$ & $(0.01)$ & $(0.03)$ & $(0.03)$ \\
\hline AFY & 0.27 & 0.23 & 0.20 & 0.20 & 0.96 & -0.24 & -0.16 & -0.39 & 0.18 \\
& $(0.04)$ & $(0.06)$ & $(0.06)$ & $(0.08)$ & $(0.01)$ & $(0.04)$ & $(0.06)$ & $(0.02)$ & $(0.02)$ \\
\hline
\end{tabular}


Notice: body weight (BW), carcass weight $(\mathrm{CW})$, carcass yield $(\mathrm{CY})$, breast weight $(\mathrm{BRW})$, breast yield (BRY), leg weight (LW), leg yield (LY), abdominal fat weight (AFW), abdominal fat yield (AFY)

The averages determined for BW and CW in the study (192.7 g and $132.1 \mathrm{~g})$ were found in agreement with the values reported for the quails slaughtered on the $8^{\text {th }}$ week by Narinç et al. (2014) and Vali (2009) (195.4-196.1 g and 130.4-132.0 g). In the study, it was discovered that BW and CW increased depending on the breeder age $(\mathrm{P}<0.05)$. Peebles et al. $(2009 \mathrm{~b})$, who examined the trait of slaughter weight in the flocks they had obtained from a flock of broiler breeders at 35 and 53 weeks of age, reported that there was a $15.48 \%$ increase for BW and a $13.93 \%$ increase for CW. The increases observed in BW and CW depending on the breeder age in this study are in agreement with the findings determined by Peebles et al. (2009b). The averages of BRW were also observed to have increased with an increase in the breeder age in the study $(\mathrm{P}<0.05)$, whereas BRY, LW, AFW and AFY were unaffected by the breeder age. The values reported by Vali et al. (2005), Sar1 et al. (2011), and Hassan et al. (2015), who investigated the traits of BRW and LW in the Japanese quails slaughtered at 8 weeks of age (41.8-50.81 g and 25.5-29.1 g), were in agreement with the findings in this study. The values of $2.27 \mathrm{~g}, 2.26 \mathrm{~g}$ and $2.20 \mathrm{~g}$, reported for AFW by Sarica et al. (2005), Hyankova et al. (2008), and Narinç et al. (2014), were found in agreement with the average of AFW (2.25 g) in this study. In a study carried out by Narinç et al. (2014), it was put forward that the trait of CY was $73.7 \%, 72.0 \%, 70.0 \%$, and $69.1 \%$ in the quails slaughtered at 5, 6, 7, and 8 weeks of age, respectively and that the carcass yield decreased due to the increases in abdominal fat and inedible parts with an increase in the slaughter age. The average of CY for the quails slaughtered on the 8th week in the study concerned and the average detected in this study $(69.07 \%)$ were found in agreement. In the study, it was established that the average of CY decreased with an increase in the breeder age. The values detected for BRY and LY $(25.98 \%$ and $15.32 \%$, respectively) were found in agreement with the findings by many researchers (Mori et al., 2005; Vali et al., 2005; Ghosh et al., 2008; Narinç and Aksoy, 2012; Lotfi et al., 2011; Sarı et al., 2011) (22.77-31.11\% and 13.50-18.84\%, respectively). The value obtained for AFY (1.15\%) was found in agreement with the value reported by Narinç et al. (2014) (1.14\%), higher than the values reported by Akşit et al. (2003) and Lotfi et al. (2011) (0.71-0.80\%), and lower than the value reported by Sarica et al. (2005) $(1.38 \%)$.

Caron et al. (1990) reported that the females (161.7 g) had higher averages than the males $(150.9 \mathrm{~g})$ in terms of slaughter weight in quails; on the contrary, the average of carcass yield for males (71.7\%) was higher than the average for females (65.9\%). Having obtained similar findings, Türkmut et al. (1999) reported that the averages of carcass yield and abdominal fat for the male quails $(72.52 \%$ and $1.48 \%$, respectively) were higher than the averages for the females $(62.70 \%$ and $1.00 \%$, respectively). Lotfi et al. (2011) reported that the female quails were $27.6 \mathrm{~g}, 7.2 \mathrm{~g}, 4.5 \mathrm{~g}$, and $0.6 \mathrm{~g}$ heavier than the males in terms of live weight, carcass weight, breast weight, and leg weight, respectively. In the same study, it was reported that the carcass, breast and leg ratios of the males were $4.3 \%, 0.3 \%$, and $1.3 \%$ higher, respectively. The differences detected in this study for the slaughter \& carcass traits in terms of sexes are in agreement with the findings reported by Caron et al. (1990), Türkmut et al. (1999), and Lotfi et al. (2011).

In the study, the heritabilities for BW were estimated to be moderate as $0.37,0.33,0.32$, and 0.32 according to the flocks obtained at 12, 16, and 20 weeks of age and in general, respectively. The literature contains no study which investigates the effects of breeder age on the genetic parameter estimations for slaughter and carcass traits in poultry. The heritabilities of CW were found at high levels (0.40-49), but the general heritability was found moderate $(0.36)$ in the flocks obtained at different breeder ages in the study. Various researchers reported that the heritability estimates for BW and CW in poultry were at moderate and high levels (Toelle et al., 1991; Gaya et al., 2006; Narinç et al., 2010; Daikwo et al., 2013). In the study, a heritability estimation (0.36) for CW was found lower than the values reported by Vali et al. (2005), Sarl et al. (2011), and Lotfi et al. (2011) (0.44-0.71), but higher than the value (0.22) reported by Khaldari et al. (2011). When the flocks were considered in general in the study, moderate heritability estimations $(0.27$ and 0.30) were found for BRW and LW. In agreement with the results of the study, the heritabilities for BRW were estimated as $0.35-0.38$ by Akşit et al. (2003), as 0.26 by Vali et al. (2005), as 0.23 by Khaldari et al. (2011), and as 0.36 by Narinç et al. (2010). The moderate heritability estimation found for LW was in agreement with the value (0.28) reported by Vali et al. (2005), the value (0.34) reported by Narinç et al. (2010), and the value (0.39) reported by Daikwo et al. (2013). 
In the study, the heritabilities estimated for CY in the flocks obtained when the breeders were at 12 , 16 , and 20 weeks of age $(0.16,0.11$, and 0.15 , respectively) and the heritability estimated when all flocks were evaluated collectively (0.14) were found at a low level. The findings concerned were found in agreement with the heritabilities estimated for CY by Vali et al. (2005), Narinç et al. (2010), Lotfi et al. (2011), Akşit et al. (2003), and Akbernejad et al. (2015) (0.11, 0.11, 0.12, 0.18, and 0.17, respectively). Similarly, the heritabilities estimated for BRY and LY were also found in agreement with the findings by most researchers (Toelle et al., 1991; Vali et al., 2005; Narinç et al., 2010; Lotfi et al., 2011; Akbernejad et $a l ., 2015)$. The heritability for AFY was estimated as 0.16 for the flocks obtained at different breeder ages but as 0.18 when all flocks were taken into consideration. The literature contains estimations of low to moderate heritabilities for AFY in quails, which is in agreement with the results of the study (Akşit $e t$ al., 2003; Narinç et al., 2010; Lotfi et al., 2011).

Both when all data were analyzed and when the data in the breeder age groups were analyzed individually, it was determined that the genetic correlations between $\mathrm{BW}$ and $\mathrm{CW}$, between $\mathrm{BW}$ and $\mathrm{BRW}$, and between BW and LW were positive and quite high (0.85-0.98). The genetic correlations between BW and $\mathrm{CW}$, between BW and BRW, and between BW and LW estimated in this study were found in agreement with the values reported by Vali et al. (2005), Sar1 et al. (2011), and Lotfi et al. (2011). Constant age weights were used as the criterion for selection in most of the selection practices carried out in Japanese quails. The carcass traits were also indirectly developed with the method of selection employed so due to the high heritabilities for the constant age weights and owing to the high genetic correlations between these traits and the slaughter and carcass traits (Narinç et al., 2010). However, the genetic correlations between slaughter weight and the traits of carcass ratio, breast ratio, and leg ratio (when all data were evaluated) were estimated as $-0.42,-0.31$, and -0.44 , respectively. In the study, the genetic correlations between BW and AFW and between BW and AFY were estimated as 0.70 and 0.27 . Besides, the genetic correlation between BW and CY was also estimated as -0.42 . According to these results, the negative genetic correlation between BW and CY indicates that the increase in weight occurred, to some extent, with muscular development but later an increase in weight due to sexual organs and finally due to fattening took place with the increased age. In the study, the genetic correlations between AFW and BW, between AFW and CW, between AFW and BRW, and between AFW and LW were estimated as positive and at moderate to high levels. These results are parallel with the findings by a large number of researchers (Akşit et al., 2003; Narinç et al., 2010; Lotfi et al., 2011).

\section{Conclusion}

Even though it was observed in the study that many important traits, primarily slaughter weight, carcass weight, and breast weight, increased with an increase in the breeder age, it was discovered that there was a decrease in the carcass yield. Nevertheless, it was established that this had no significant effect on the genetic parameter estimations. In this case, it is essential that the test flocks to be obtained from parent flocks be obtained at the optimum age(s) in the breeding studies in which the slaughter \& carcass traits are used as the criteria for selection; however, it is supposed that this will not affect the breeder value estimations very much. The heritability estimations for BW, BRW, CW, and AFW and the genetic correlations between them were found at moderate and high levels in the research. It is understood that by using the live weight at a constant age as the criterion for selection, the trait concerned can easily be developed. In this way, it might be expected to achieve an indirect increase in the carcass weight too. Nevertheless, it is likely to encounter serious fattening problems with a long-term selection practice due to the positive and high genetic correlation observed between the carcass weight and the abdominal fat weight (0.70). Fattening may result in such undesired cases as a regression in feed conversion, the worsening of carcass quality, and low fertility. As a result of using the trait of CY as the criterion for selection instead of $\mathrm{BW}$ or $\mathrm{CW}$, it is probable that there will be a decrease in the trait of abdominal fat ratio in a long-term selection study due to the negative genetic correlation between them. Besides, it is thought that the most successful results will be obtained as a result of the selection to be applied through the determination of the multi-trait breeder values also by determining such traits as feed consumption, feed conversion ratio, and fertility, none of which were detected in the research. 


\section{Acknowledgements}

This study was funded with the number NKUBAP.03.GA.16.033 by Namık Kemal University Scientific Research Projects Coordination Unit.

\section{References}

[1] Akbarnejad S, Zerehdaran S, Hassani S, Samadi F and Lotfi E. Genetic evaluation of carcass traits in Japanese quail using ultrasonic and morphological measurements. British Poultry Science, 56:293298. 2015.

[2] Akşit M, Oğuz İ, Akbaş Y, Altan Y and Özdoğan M. Genetic variation of feed traits and relationships to some meat production traits in Japanese quail (Coturnix coturnix Japonica). Archiv für Geflügelkunde, 2003; 67:76-82.

[3] Alfonso-Torres KA, Gargaglioni LH, Pizauro JM, Faria Filho DE, Furlan RL and Macari M. Breeder age and bone development in broiler chicken embryos. Arquivo Brasileiro De Medicina Veterinaria Zootecnia, 2009; 61:219-226.

[4] Caron N, Minvielle F, Desmarais M and Poste LM. Mass selection for 45-day body weight in Japanese quail: Selection response, carcass composition, cooking properties, and sensory characteristics. Poultry Science, 1990; 69:1037-1045.

[5] Çabuk M, Bozkurt M, Alçiçek A, Akbaş Y and Küçükyılmaz K. Effect of a herbal essential oil mixture on growth and internal organ weight of broilers from young and old breeder flocks. South African Journal of Animal Science, 2006; 36:135-141.

[6] Daikwo SI, Momoh OM and Dim NI. Heritability estimates of genetic and phenotypic correlations among some selected carcass traits of Japanese quail (Coturnix coturnix japonica) raised in a subhumid climate. Journal of Biology, Agriculture and Healthcare, 2013; 3:60-65.

[7] El Sabry MI, Yalçın S and Turgay İG. Interaction between breeder age and hatching time affects intestine development and broiler performance. Livestock Science, 2013; 157:612-617.

[8] Gaya LG, Ferraz JB, Rezende FM, Mourão GB, Mattos EC, Eler JP and Michelan Filho T. Heritability and genetic correlation estimates for performance and carcass and body composition traits in a male broiler line. Poultry Science, 2006; 85:837-843.

[9] Ghosh HK, Halder G, Samanta G and Koley S. Effect of dietary supplementation of organic acid and mannan oligosaccharide on the plasma minerals and carcass traits of Japanese quail (coturnix coturnix Japonica). Research in Veterinary Science Journal, 2008; 1:44-49.

[10] Hassan K H, Ali RA, Homam AAY, Haeder TA and Dalal AAAW. Effect of Variety, Age and sex in some productive traits in Japanese quail in Iraq. American Journal of Bio Science, 2015; 3:55-58.

[11] Hulet R, Gladys G, Hill D, Meijerhof R and El-Shiekh T. Influence of eggshell embryonic incubation temperature and broiler breeder flock age on posthatch growth performance and carcass characteristics. Poultry Science, 2007; 86:408-412.

[12] Hyankova L, Novotna B and Darras VM. Divergent selection for shape of growth curve in Japanese quail. 4. Carcass composition and thyroid hormones. British Poultry Science, 2008; 49:96-102.

[13] İpek A and Sözcü A. The effects of broiler breeder age on intestinal development during hatch window, chick quality and first week broiler performance, Journal of Applied Animal Research, 2015; 43:402408.

[14] Joseph SN and Moran Jr ET. Effect of flock age and post emergent holding in the hatcher on broiler live performance and further-processing yield. The Journal of Applied Poultry Research, 2005; 14:512-520.

[15] Khaldari M, Mehrabani Y, Pakdel A, Nejati AJ and Peer B. Response to family selection and genetic parameters in Japanese quail selected for four week breast weight. Archiv Tierzucht, 2011; 54:212223. 
[16] Lotfi E, Zerehdaran S and Ahani Azari M. Genetic evaluation of carcass composition and fat deposition in Japanese quail. Poultry Science, 2011; 90:2202-2208.

[17] Mori C, Garcia CA, Pavan AC, Piccinin A, Cachoni C and Pizzolante CC. performance and carcass yield of four quail genetic groups selected for meat production. The Revista Brasileira de Zootecnia, 2005; 34:870-876.

[18] Mrode RA. Linear models for the prediction of animal breeding values. Second Edition, CABI Publishing, 875 Massachusetts Avenue Cambridge, 2005; MA 02139 USA.

[19] Narinç D and Aksoy T. Effects of mass selection based on phenotype and early feed restriction on the performance and carcass characteristics in Japanese quails. Journal of the Faculty of Veterinary Medicine Kafkas University, 2012; 18:425-430.

[20] Narinç D, Karaman E and Aksoy T. Estimation of genetic parameters for carcass traits in Japanese quail using Bayesian methods, South African Journal of Animal Science, 2010; 40:342-347.

[21] Narinç D, Karaman E and Aksoy T. Effects of slaughter age and mass selection on slaughter and carcass characteristics in two lines of Japanese quail. Poultry Science, 2014; 93:762-769.

[22] Onbaş1lar EE, Poyraz O and Çetin S. Effects of breeder age and stocking density on performance, carcass characteristics and some stress parameters of broilers. Asian-Australasian Journal of Animal Sciences, 2008; 21:262-269.

[23] Peebles ED, Doyle SM, Pansky T, Gerard PD, Latour MA, Boyle CR and Smith TW. Effects of breeder age and dietary fat on subsequent broiler performance. 1.Growth, mortality, and feed conversion. Poultry Science, 1999a; 78:505-511.

[24] Peebles ED, Doyle SM, Pansky T, Gerard PD, Latour MA, Boyle CR and Smith TW. Effects of breeder age and dietary fat on subsequent broiler performance. 2. Slaughter yield. Poultry Science, 1999b; 78:512-515.

[25] Sar1 M, Tilki M and Saatci M. Genetic parameters of slaughter and carcase traits in Japanese quail (Coturnix coturnix Japonica). British Poultry Science, 2011; 52:169-172.

[26] Sarıca S, Çorduk M and Kılınç K. The effect of dietary L-carnitine supplementation on growth performance, carcass traits and composition of edible meat in Japanese quail (Coturnix coturnix japonica). The Journal of Applied Poultry Research, 2005; 14:709-715.

[27] Shanawany M. Hatching weight in reation to egg weight in domestic birds. World's Poultry Science Journal, 1987; 43:107-115.

[28] Şahan U, Ipek A and Sözcü A. Yolk sac fatty acid composition, yolk absorption, embryo development, and chick quality during incubation in eggs from young and old broiler breeders. Poultry Science, 2014; 93:2069-2077.

[29] Toelle VD, Havenstein GB, Nestor KE and Harvey WR . Genetic and phenotypic relationship in Japanese quail. Poultry Science, 1991; 70:1679-1688.

[30] Triyuwanta C. Leterrier J, Brillard P and Nys Y. Maternal body weight and feed allowance of breeders affect performance of dwarf broiler breeders and tibial ossification of their progeny. Poultry Science, $1992 ; 71: 244-254$.

[31] Türkmut L, Altan O, Oğuz İ and Yalçın S. Effects of selection for four week body weight on slaughter, carcass, and abdominal fat and some organ weights and blood serum parameters in Japanese quail. Turkish Journal of Veterinary and Animal Sciences, 1999; 23:63-68.

[32] Ulmer-Franco AM, Fasenko GM and O'Dea Christopher EE.. Hatching egg characteristics, chick quality, and broiler performance at 2 breeder flock ages and from 3 egg weights. Poultry Science, 2010; 89:2735-2742. 
[33] Vali N. Probiotic in quail nutrition: A review. International Journal of Poultry Science, 2009; 8:12181222.

[34] Vali N, Edriss MA and Rahmani HR. Genetic parameters of body and some carcass trait in two quail strains. International Journal of Poultry Science, 2005; 4:296-300.

[35] Vieira SL and Moran Jr ET. Eggs and chicks from broiler breeders of extremely different age. Journal of Applied Poultry Research, 1998; 7:372-376.

[36] Wyatt CL, Weaver Jr WD and Beane WL. Influence of egg size, eggshell quality and posthatch holding time on broiler performance. Poultry Science, 1985; 64:2049-2055.

[37] Yalçın S, Oğuz I and Ötleş S. Carcass characteristics of quail (Coturnix coturnix Japonica) slaughtered at different ages. British Poultry Science, 1995; 36:393-399.

[38] Zerehdaran S, Vereijken AL, van Arendonk JA and van der Waaij EH. Estimation of genetic parameters for fat deposition and carcass trait in broilers. Poultry Science, 2004; 83:521-525. 